\title{
La crisis del sistema liberal en Italia
}

\author{
ADRIAN LYTTELTON
}

Mi intención no es tanto describir en orden cronológico la crisis del sistema liberal en Italia, como señalar algunos problemas importantes. Principalmente desearía plantear el problema de en qué manera las debilidades estructurales del sistema enlazan con la crisis final. De momento, con el fin de dar unas sencillas referencias cronológicas para ayudar a entender los temas que abordaré en lo sucesivo propongo articular la crisis en tres fases:

1. De 1911 a 1914: guerra de Libia y crisis del equilibrio giolittiano.

2. De 1914 a 1918: guerra europea y crisis del control parlamentario.

3. De 1919 a 1922: posguerra y crisis del orden público.

Esta tercera fase puede a su vez subdividirse en dos períodos, el «bienio rojo» (1919-1920) y el «bienio negro» (1921-1922). Hay también un importante epílogo, al cual no pienso dedicarle mucho tiempo aquí: por qué tras la marcha sobre Roma y hasta 1925 coexisten el fascismo y las otras fuerzas políticas, y hay que esperar hasta 1925-1926 para que se produzca la ruptura decisiva e irreversible con el estado liberal.

Resulta bastante obvio que, respecto a los regímenes "clásicos" de gobierno liberal representativo, el caso italiano presenta muchas "anomalías". Varios historiadores han insistido sobre la continuidad de fondo entre las estructuras del estado liberal y las del estado fascista, aunque bajo mi punto de vista esta conclusión peca de un excesivo formalismo. Es cierto que muchos de los instrumentos y de las instituciones del estado liberal, sobre todo los poderes muy amplios y difíciles de controlar asignados al ejecutivo para el mantenimiento del orden público, pudo utilizarlos el fascismo en la fase de transición a la dictadura. Sin embargo, me parece que la etapa giolittiana, al menos en los años 1901-1911, rerpresenta una relativa normalización del régimen liberal italiano sin duda ayudada tanto por las condiciones generales de estabilidad internacional como por la particular situación de Italia en el sistema internacional.

La crisis interna del régimen liberal italiano se encuadra en la crisis general del sistema europeo. En las tres fases se da una interdependencia 
estrecha entre la crisis internacional y la crisis interna. Italia, por ser la más débil de las grandes potencias, sufre en gran medida las iniciativas ajenas, aunque en 1914-1915 elige bastante por su cuenta la entrada en guerra. No tengo intención de deternerme mucho en este aspecto, pero es necesario insistir en que el papel del estado en el sistema internacional es un factor estructural y coyuntural de primera importancia.

Desde 1860 existe un nexo entre las demandas excesivas derivadas del papel que le correspondía a Italia en el sistema internacional y los desórdenes internos, sobre todo agrarios, un nexo que percibieron con claridad algunos observadores contemporáneos, como el autor principal del gran Informe Agrario, el ilustre conservador Stefano Jacini. La guerra de Libia primero y la gran guerra después trastornaron por completo la estructura del estado liberal, al destruir entre otras cosas la «normalidad» financiera, la era de las balanzas equilibradas y de la estabilidad de la lira, y por tanto la confianza del público y sobre todo de las clases medias en la funcionalidad del régimen.

Desearía destacar que Giolitti defendía explícitamente la tesis de que la guerra no tendría que influir en las directrices fundamentales de la política interior. Pero, como ha escrito un historiador alemán, el movimiento imperialista ya había asumido las connotaciones "de un movimiento de masas antigubernamental que haría siempre más precaria la visión giolittiana de la relación entre política exterior e interior (y) amenazaba con destruir la separación entre política exterior e interior propia de la línea de Giolitti, el dominio exclusivo de la Corona y del tándem Presidencia de Gobierno-Ministro de Asuntos Exteriores». Esta movilización de la opinión pública fue precursora de la aún más amplia que se produjo en favor de la entrada en guerra. De nuevo el gobierno trató de conservar de alguna forma la autonomía de la política exterior, pero, sin embargo, no pudo evitar una violenta división del país y de la clase dirigente que modificó todo el panorama político. Naturalmente la situación no era la misma, ya que el Presidente del Gobierno, Salandra, estaba en debilidad de condiciones frente a la mayoría giolittiana y trató de aprovechar la crisis para debilitar la posición de su jefe. En este cometido se sirvió de la crítica hecha por la derecha a la falta de preparación militar. Pero parece estar comprobado que no quería la intervención de las masas, como sucedió en mayo de 1915.

El perdedor en estas crisis fue el Parlamento. Perdió en dos frentes, porque por un lado sufrió la reafirmación de la tradicional independencia de la Corona -y por tanto del Gobierno-- en temas de política exterior y militar, y por otro sufrió - al menos en mayo de 1915- el chantaje de las masas militantes que acompañó a la pérdida del control ideológico sobre las clases medias. 
La crisis del control parlamentario se dio ya en la guerra de Libia, cuando Giolitti mantuvo cerrada la Cámara cinco meses tras el inicio de la guerra. Durante la gran guerra, el control parlamentario sobre el gasto público y sobre los mecanismos de la administración se mostró cada vez más ineficaz.

El porcentaje del gasto público sobre el PIB, que había ya aumentado del 14,2 por cien en 1907 al 18,3 por cien en 1912, se dobló alcanzando el 41 por cien en 1917. También los mecanismos internos de control administrativo se debilitaron frente a la alianza entre poderosos grupos industriales y sectores de la burocracia. Los industriales tenían casi libertad de acción para determinar los costes de los aprovisionamientos: se llegó también a contabilizar el impuesto sobre el beneficio como un elemento al calcular el precio - concesión que evidentemente convierte en fantasía cualquier intento serio de política financiera.

¿Se podría explicar la crisis de este estado sólo a través del análisis de estos problemas estructurales? Creo que se correría el riesgo de subvalorar los elementos nuevos y en parte imprevisibles aportados por la gran guerra. Sobre todo resultaría incomprensible la solución dada a la crisis del estado liberal -el fascismo- sin tener en cuenta los efectos sociales, así como ideológicos y psicológicos, de la guerra. Por tanto intentaré sugerir alguna de las conexiones entre factores estructurales y coyunturales. A mi entender Juan Linz plantea el problema de forma correcta cuando escribe que las estructuras constituyen "una serie de oportunidades y de constricciones para los actores sociales y políticos, ya sean de índole económica o institucional, que pueden conducir a resultados diversos".

Los primeros intérpretes importantes de la crisis del estado liberal y del fascismo en el plano historiográfico, Angelo Tasca y Gaetano Salvemini, conceden mucha importancia a los errores de los protagonistas y a la limitada visión política de todas las fuerzas democráticas y socialistas. Tenían además como tarea principal la de contar una historia desconocida en muchos aspectos o desvirtuada por la propaganda fascista. Ambos habian participado directamente en las luchas políticas de la época. En aquel tiempo Tasca militaba en el Partido Socialista Italiano y más tarde lo haría en el recién creado Partido Comunista de Italia; Salvemini, tras haber pertenecido al PSI a principios de siglo, se había convertido en un demócrata independiente. En los años treinta, cuando escribían sus obras principales, Tasca ya había sido expulsado del PC italiano por «desviacionismo de derechas". A pesar de sus diferentes posturas se les puede considerar unos herejes del socialismo, especialmente versados en el análisis de los errores históricos de aquella que había sido la principal fuerza 
organizada y el principal vehículo de las esperanzas populares de la etapa anterior al fascismo.

Sin embargo, yo querría centrarme en su crítica al régimen liberal. Salvemini era conocido como uno de los críticos más feroces del sistema giolittiano, del liberalismo del período anterior a la guerra. Aun así en sus Conferencias de Harvard de los años treinta, reconocía, autocriticándose incluso, que una visión demasiado pesimista del gobierno parlamentario había legitimado las pretensiones fascistas, como en efecto ocurrió en cierto modo. Cuando, por ejemplo, describía el atraso de Italia en los tiempos de la unificación, no lo hacía para deducir que el fascismo sencillamente revelaba las taras de la historia italiana, muy al contrario lo que trataba de explicar a un auditorio probablemente escéptico, era lo cambiada que estaba Italia en 1919. Por dar un solo ejemplo: la tasa de analfabetismo se había reducido aproximadamente a la mitad entre 1860 y 1911. A la realidad del progreso económico y civil, Salvemini contraponía las aspiraciones, del todo irreales, de una parte de la intelligentsia, envenenada por el "cáncer romano-imperial» con sus «sueños de primacías imposibles». La consecuencia era que ningún grado de progreso podía satisfacerles. La amplia difusión de una mentalidad de estas características, de un nacionalismo genérico pero apasionado, hacía que la opinión pública estuviera abierta a la influencia del grupo, reducido pero impetuoso, de los nacionalistas organizados, sin apenas base electoral, pero con muchas simpatías en el ejército, la diplomacia, la gran industria y la prensa.

La crisis de la posguerra es, tanto para Salvemini como para Tasca, "una crisis de crecimiento", debida en lo fundamental no al atraso sino al desarrollo. Según Tasca, en efecto, la ocasión histórica de 1919 había sido la oportunidad de realizar «una revolución democrática». Llega a afirmar que era necesaria una revolución burguesa, como en Rusia en marzo de 1917, juicio histórico éste de un esquematismo insólito. La actitud de Salvemini es, en su conjunto, más moderada. Se aprecia la diferencia en sus comentarios acerca de la monarquía. Según el antiguo revolucionario Tasca, ésta se había convertido ya en un obstáculo de escasa entidad, al que las masas habrían podido eliminar con facilidad si sus dirigentes hubiesen tenido una estrategia política coherente. En su opinión, "casi todos están por la abolición de la monarquía, y se resignan a su desaparición": entre los exiliados estaba ya difundida la consigna que prevalecería en la Asamblea Constituyente de 1946. En cambio, según Salvemini los socialistas maximalistas habian infravalorado peligrosamente la fuerza de la institución monárquica. Al protestar ruidosamente por la inauguración real del nuevo parlamento de 1919, habrian atacado el símbolo de la monarquía constitucional y estimulado las tendencias antiparlamentarias 
de los oficiales del ejército. Me parece que resulta más convincente la visión de Salvemini. En efecto, las fuerzas que aún estaban a favor de la monarquia no escaseaban. No conviene olvidar que, al contrario que Rusia en 1917 o Alemania en 1918, Italia ya había salido de la guerra, y además como una de las vencedoras. La lealtad monárquica, por tanto, no se había destruido ni siquiera entre los jóvenes ex oficiales y combatientes, aunque en su mayoria defendieran posturas democráticas. La tradición del Risorgimento, para la que libertad, nación y monarquía formaban una triada inseparable, conservaba aún un fuerte valor simbólico. Por otra parte, los católicos del nuevo Partito Popolare, a pesar de su hostilidad al estado surgido del Risorgimento, no sentían ningún estusiasmo por la agitación republicana, demasiado unida por razones históricas al anticlericalismo. En cambio resulta convincente la idea de que la crisis de la posguerra deba verse como una transición fallida de un sistema liberal oligárquico a una democracia efectiva, con partidos de masas fuertes.

La situación parlamentaria determinada por las elecciones de 1919, las primeras llevadas a cabo con el sistema de representación proporcional, fue emblemática. Más de la mitad de los escaños fue para los partidos de masas: los socialistas consiguieron 156 escaños; y el nuevo Partito Popolare de Don Sturzo tuvo 100. Frente a estos dos partidos, muy enfrentados en el terreno ideológico pero con una sólida organización y capacidad movilizadora, estaban los grupos desperdigados de la democracia liberal, de los radicales, y de los socialreformistas (salidos del PSI cuando la guerra de Libia). Estos grupos y también el formado por los combatientes, tenían límites mal definidos y una disciplina política escasa o inexistente. A pesar de todo, la representación proporcional tuvo un cierto efecto aglutinador y por lo menos aumentó mucho la posición negociadora de los grupos parlamentarios respecto al ejecutivo, por lo que Giolitti siempre se mostró firme partidario de la reforma.

Salvemini dedica algunas páginas de su análisis a los orígenes de la "parálisis parlamentaria" de la posguerra, que atribuye a la obstrucción de los socialistas, a las divisiones internas de las fuerzas constitucionales, a su falta de confianza en los popolari, y a otros factores más coyunturales. Las medidas económicas esenciales se realizaban mediante el mecanismo del decreto ley, evitando los retrasos parlamentarios. El resultado era que se extendía la idea de que el parlamento podría "eliminarse del sistema político italiano por ser un órgano inútil».

Llegados a este punto, para entender la crisis de las instituciones parlamentarias de la posguerra conviene referirse al funcionamiento general del régimen parlamentario desde la unificación. En primer lugar querría abordar el problema de la composición de la clase política. Recientemente 
el politólogo Paolo Farneti ha abordado el tema de la clase política parlamentaria en su artículo "Crisis de la democracia italiana» (incluido en la obra colectiva dirigida por Juan Linz) y, más en detalle en su ensayo sobre "Sistema político y sociedad civil». El concepto del que parte Farneti es el de "desfase" - lag- entre la sociedad civil y la sociedad política. Frente al brusco avance dado por la sociedad de clases de resultas de la guerra, a la movilización política sin precedentes de los obreros y de los campesinos, permanecia «una élite política todavía ligada a un punto de vista (...) perteneciente a la era giolittiana". Es decir que "pensaban en términos de personalidades y no de grupos, de clientelas en vez de partidos organizados, y de clientelismo más que de política de masas". Además Farneti proporcionaba un análisis sociológico de la clase política italiana del período 1860-1915, que sirve para explicar esta situación. Según Farneti, que se refiere sobre todo a la época giolittiana, se trata de una clase política estable en una sociedad cambiante. "El predominio de los abogados" permaneció intacto, así como la preponderancia política de la clase media urbana de las ciudades pequeñas y medianas, de economía principalmente agrícola. Si la representación de la propiedad territorial se redujo notablemente, no lo hizo a favor de los industriales o de otros representantes de las nuevas fuerzas económicas. Aunque requiera comprobación, resulta de gran interés su tesis de que la unión entre agrarios e industriales era más estrecha, más "orgánica", que la que existía entre estas dos clases y los abogados (el análisis se basa en las declaraciones de la "segunda profesión"). Dicho de otra manera, los abogados no eran en gran medida los «delegados" del gran capital o de la gran propiedad o los intermediarios directos de sus intereses. Por el contrario, «a la abogacía se le dejó el papel de organizar, a través del trabajo en las notarías, a la clase media urbana y rural y a buena parte de las clases populares". Se tendría que precisar que esto no quiere decir que los abogados no estuvieran interesados en el tema de la propiedad. Pero es probable $-y$ repito que la hipótesis de Farneti es aún provisionalque expresasen los intereses de la media y pequeña propiedad burguesa más que de la gran propiedad y del capitalismo agrario.

Fue precisamente esta estructura de la clase política la que a partir de los años ochenta se convirtió en el centro de atención de los polemistas del nuevo sector empresarial, empezando por el gran estratega del giro proteccionista, Alessandro Rossi. Esta polémica contraponía a los «productores" de la industria los "parásitos de la clase parlamentaria y de la burocracia", unidos a la antigua tradición humanística y por tanto al margen de las exigencias del nuevo mundo tecnológico.

Paradójicamente, sin embargo, los propios industriales eran objeto de una polémica similar. Pareto, y en general casi toda la tradición liberal, 
consideraba a los grandes industriales como los protagonistas de una estrategia de "expoliación» en la que actuaban como cómplices la clase parlamentaria y el gobierno. Ahora bien, estas fracturas internas del régimen liberal tuvieron una gran importancia en relación con la crisis. Por un lado el nacionalismo y más tarde el fascismo, se apropiaron de las consignas de los "productores". Y fue en este terreno ideológico en el que se produjo la convergencia con un ala del sindicalismo revolucionario, contrario a la mediación parlamentaria. Es bien sabido que desde 1917 el Popolo d'Italia de Mussolini se subtituló "el periódico de los productores y de los combatientes". En 1910 se formó la primera Confederazione Italiana dell'industria, precursora de la famosa Confindustria (Confederazione Generale dell'Industria), fundada de nuevo en 1920, que aunque no tuviera la fuerza que alcanzaría en la posguerra, era ya un signo importante. La acción política de los industriales tendía ya a mostrar claramente sus divergencias con el sistema parlamentario y con los grupos políticos tradicionales. En 1911 la Lega Industriale de Turín denunciaba la separación existente centre las gentes que producen y pagan y la facción que gobierna", constituida en su mayoría por abogados de provincias, profesores y funcionarios del estado. La nueva política de los grupos de presión organizados conllevaba también una alianza en la práctica con las asociaciones agrarias. Al único grupo político que se respetaba era al nacionalista, que contaba, sin embargo, con una representación escasa. Por otra parte, la elección de los industriales estaba casi forzada al no existir ningún partido liberal o conservador importante. Además, según Roberto Vivarelli, Giolitti daba primacía a la intervención caso por caso, a menudo dejada en manos de los prefectos. La gran libertad de actuación de los prefectos cada vez era peor aceptada en una sociedad en que los grandes grupos de presión empezaban a superar el fraccionamiento tradicional y el localismo. Sin duda, Giolitti se enfrentaba a un dilema de difícil solución. El estado no podía adoptar una actitud de neutralidad perfecta y no intervenir en los conflictos sociales sin arriesgarse a un grave deterioro de toda la escena política. El liberalismo giolittiano se basaba en la eficacia de sus mediaciones sociales, pero cuando la acción gubernamental se hizo demasiado libre se corría el riesgo de que la imagen del estado como "árbitro" se viera fuertemente dañada. Un ejemplo muy significativo es el de la presión a que fueron sometidos los industriales de la metalurgia de transformación de Turín en 1913, para hacerles desistir de un cierre patronal, llegando el gobierno a amenazar con expulsar de Italia al presidente de la Lega Industriale, Bonnefon Craponne, de nacionalidad francesa. En la posguerra el tipo de intervención al que los prefectos estaban acostumbrados se demostró contraproducente. La práctica de la conciliación entre las fuerzas políticas más sólidas contribuyó en un primer mo- 
mento a convencer a los sectores propietarios de que el estado ya no les defendía, y más tarde al afianzamiento de la ilegalidad fascista. Es cierto que no se pueden achacar todos o casi todos los males a Giolitti. La falta de autonomía de la administración tanto judicial como política era uno de los problemas de siempre del orden liberal italiano. A ello se añade que, incluso debido la maestría del propio Giolitti, su dirección sin igual sobre el aparato administrativo no eliminó sino que incluso reforzó la impresión de que se vivía bajo el gobierno de «hombres" y no de «leyes».

En el plano directamente político, como es bien sabido, principalmente se acusa a Giolitti de haber impedido - o descuidado- la formación de un partido liberal fuerte y también de haber debilitado y hecho perder carácter a otras fuerzas políticas, como los radicales. Una vez más sería un grave error dar una visión demasiado personalizada de este problema, como les sucedía con frecuencia a los críticos de la época. Giolitti tenía conciencia del problema, por lo menos en los comienzos de su largo mandato. Entonces había criticado la irracionalidad del fraccionamiento liberal en el parlamento y había auspiciado su reorganización en torno a los "grandes principios". Puede que el momento decisivo para la estructura de los partidos fuera el período de 1876 a 1882, cuando el modelo "transformista" de Depretis, que veía al gobierno como la fuerza que cohesionaba a la mayoria, se impuso al modelo propuesto por otros dirigentes de la izquierda que trataban de crear en el país una organización partidista duradera. Por otra parte las dificultades para crear una organización nacional de tipo moderno en un país fragmentado y dualista no eran pocas. Resulta sin duda significativo que fueran los conservadores Sonnino, Salandra, y sobre todo el director del Corriere della Sera, Luigi Albertini, los que presionaran para crear un partido liberal único. Las mediaciones giolittianas habrían sido menos flexibles, y el peso de los intereses establecidos puede que mayor.

Un segundo problema es el de la trama caciquil del Mezzogiorno y su naturaleza conflictiva. Interesa señalar que durante la etapa giolittiana este problema cada vez era más difícil de solucionar, ya que la mayoría liberal se hizo cada vez más meridional, debido a la pérdida de sus posiciones en el norte $y$ en el centro de Italia por el avance de los socialistas y también de los católicos. En los últimos tiempos incluso los radicales vieron también desplazarse su centro de gravedad hacia el Mezzogiorno. La cumbre del proceso se alcanza en 1919, cuando los liberales y el resto de los grupos afines estaban en franca minoría en el norte, pero en cambio controlaban aún la gran mayoría de las circunscripciones del sur. En 1924, cuando un amigo pidió a Giolitti que se adhiriera al nuevo partido liberal, organizado, por ironías del destino, pocas semanas antes de la Marcha sobre Roma, respondió que el proyecto de reunir a todas las fuerzas 
constitucionales estaba destinado al fracaso. ¿Por qué? Porque en el Mezzogiorno la realidad de estas fuerzas eran las clientelas locales armadas, en sentido literal, las unas contra las otras.

El problema presenta también otra cuestión, incluso más importante. ¿Por qué las bases sociales del sistema de representación liberal se debilitaron? La respuesta resulta obvia en lo que se refiere a las áreas industrializadas 0 urbanizadas. Con la excepción de islotes en que grandes industriales como los Rossi, los Marzotto, los Crespi y algunos otros ejercian un control paternalista, la hegemonía liberal no alcanzaba al proletariado. Este límite se hizo cada vez más evidente en los años 1886-1898. El proyecto giolittiano no se planteaba de hecho "reconquistar" a los sectores proletarios y artesanos, sino más bien conseguir que aceptasen el sistema de las «instituciones» como se decía, refiriéndose sobre todo a la monarquía, a través de una mediación del partido socialista. Esta «mediación" pudo funcionar sólo mientras que el partido estuvo controlado por el ala reformista. Por primera vez en 1904 el triunfo en el partido de la facción "intransigente" obligó a Giolitti a un cambio de estrategia que le supuso aceptar la ayuda de los votos católicos, concedida por Pío X debido sobre todo al miedo al socialismo. Fue también en esas elecciones en las que llegó a cristalizar la famosa "mayoría" meridional, gubernamental, de los llamados ascari.

En 1911-1912 los socialistas reformistas perdieron también el control del partido, debido esta vez a la guerra de Libia y a las ofertas de colaboración en el gobierno que hizo Giolitti, provocándose una separación entre la derecha reformista (Bissolati y Bonomi) y la izquierda (Turati y Treves). La consecuencia fue el triunfo del "maximalismo" y del mismo Mussolini, por entonces orador y escritor revolucionario de gran eficacia. Por razones de espacio, omitiré todo análisis detallado de los cambios sociales operados en la clase obrera y sus repercusiones políticas. Sólo querría mencionar la importancia de la guerra y de la conflictividad industrial. Al igual que en otros países ésta se relacionó con un flujo de nuevos trabajadores, recién llegados del campo, que no estaban acostumbrados a la disciplina industrial. La socialización de estos nuevos obreros se produjo en circunstancias muy difíciles debido a que gran parte de la industria estaba sujeta a unas normas de disciplina especialmente duras, las de las industrias de importancia militar. Añadamos a esto la amenaza del desempleo debido a la reconversión de las industrias bélicas al final de la guerra y el notable declive de los salarios reales, y se entenderá con facilidad el posterior proceso de redicalización de la clase obrera durante el "bienio rojo».

Por el contrario querría detenerme más en la crisis del campo, porque era precisamente allí donde el liberalismo conservaba un poder más só- 
lido. A pesar de contar con una industrialización superior, al igual que en España los liberales podian resignarse a las pérdidas urbanas siempre que conservaran el control del campo. Por tanto la pérdida de este control es quizá la razón más profunda de la crisis del sistema liberal en Italia.

Según el programa de los liberales del Risorgimento, la modernización de la agricultura no debía bajo ningún concepto trastocar las bases de la influencia social que tradicionalmente habían ejercido los propietarios. El mismo Cavour, el de actitud más "moderna" respecto a la industria, dudaba ante la perspectiva de crear un proletariado agrícola según el modelo inglés. Un sistema de aparcería o de arriendo con alguna participación en la producción, era, según él, necesario para perpetuar «los lazos de simpatía y afecto" que unían a propietarios y campesinos. Sólo una clase propietaria que conseguía conservar el respeto y la confianza de sus colonos y arrendatarios podía "dominar la marcha de la sociedad" y asegurar que ésta sería "progresiva" en vez de "destructiva y revolucionariam.

Los temores de Cavour se convirtieron en realidad en el Valle del Po a partir de los años ochenta. La masa de trabajadores sin tierra, los braceros, comenzó a organizarse en las ligas socialistas. La oleada de huelgas rurales y la continua labor organizativa no tienen paralelo en el resto de Europa. Dede 1901 los propietarios no pudieron ya contar con el apoyo incondicional del gobierno. Giolitti -y es su innovación principal- rechazó la intervención represiva sin más. A partir de 1906 las ligas, por entonces organizadas en una poderosa Federación, la Federterra, trataron de conseguir el control del mercado de trabajo a través de las oficinas sindicales de empleo. En alguna provincia como en Parma, actuaron también los sindicalistas revolucionarios organizando huelgas generales. Ante esta situación, los terratenientes reaccionaron de dos formas distintas. Por una lado buscaron el apoyo de las categorías intermedias del campo: aparceros, arrendatarios y pequeños propietarios, proponiendo en el fondo una versión actualizada del antiguo paternalismo. Por otro, en cambio, se trató de fundar asociaciones agrarias fuertes y disciplinadas, siguiendo el modelo de las patronales de la industria, y no es casualidad que esta idea fuera capitaneada por Lino Carrara, un terrateniente de la provincia de Parma, bastión del sindicalismo revolucionario. Se organizaron escuadrones de "voluntarios" con el fin de romper las huelgas, incluso mediante la violencia. Otro aspecto significativo de esta estrategia fue la alianza cada vez más estrecha con los representantes de los industriales, que se basaba también en intereses comunes en el caso de las industrias de transformación de productos agrícolas. Se formaba así un bloque clasista nuevo basado en la intransigencia ante los conflictos laborales. Esto condujo a su vez a rechazar las mediaciones gubernamentales. En 1912 el 
prefecto de Bolonia comunicaba a Giolitti que no podía mantener «un trato cordial" con los jefes de los terratenientes que "ofenden a los representantes del gobierno". En efecto habían acusado al prefecto de callarse ante las violaciones de la ley cometidas por los sindicatos para «no comprometer un programa político caracterizado por las concesiones y rendiciones continuas". La intransigencia de los nuevos terratenientes (antes y después de la guerra) era también una respuesta a la «marginación de la agricultura". Es en este sentido en el que hay que leer toda la retórica del ala intransigente del fascismo acerca de las razones de "las provincias» contra «Roma».

Antes de la guerra, al margen del Valle del Po y alguna otra zona "caliente», como Apulia, quedaban todavía muchas áreas tranquilas en el campo. Para los conservadores la aparcería implicaba un sistema de relaciones "modélico", y el tipo de contrato que más se acercaba al ideal era el de Toscana, que de hecho había sido en varias ocasiones propuesto por conservadores ilustrados, como Franchetti y Sonnino, como solución a los problemas del Mezzogiorno. Sin embargo, a partir de la unificación la creciente especialización debida al desarrollo del mercado, nacional e internacional, habia introducido cambios internos en esta relación. En 1907 Francisco Guicciardini, uno de los representantes más notables de los terratenientes de Toscana, denunciaba la devaluación que estaban sufriendo las relaciones personales entre propietario y campesino. Si bien con anterioridad había sido motivo de orgullo para los toscanos que, al contrario de lo que sucedía en el sur, "no se aplique interés entre patronos y campesinos", por esas fechas los propietarios a menudo cobraban interés sobre los anticipos y sobre las deudas contabilizados a finales del año agrícola. A ello se añadía que los nuevos métodos de la agricultura, que imponían costes más elevados, tendieran a empeorar la situación de la deuda campesina. No obstante la supremacía social y política de los grandes propietarios se mantuvo en un medio rural donde la mayoría de la población campesina vivía dispersa, donde faltaba o era débil la fuerza aglutinadora de los núcleos rurales. En 1902 y 1906 tuvieron lugar las primeras huelgas importantes, pero quedaron como fenómenos aislados. Fue la guerra la que rompió con el aislamiento tradicional del campesino poniéndolo en contacto mucho más estrecho con los obreros y proporcionándole otras experiencias. Creó los presupuestos para una movilización sin precedentes en 1919-1920: unos 500.000 aparceros de 720.000 participaron en la huelga principal.

Por las mismas fechas la ofensiva de las ligas del Valle del Po se reanudó con mayor intensidad. Se abrió camino la demanda de un cupo de mano de obra, de modo que el propietario garantizara una cuota fija de trabajo por unidad territorial. Además también las ligas católicas, que 
contaban con una base organizativa sobre todo entre los arrendatarios y colonos del Veneto y de la Lombardía, pero que también estaban presentes en muchas otras regiones, incluidas las del Mezzogiorno, tuvieron una actividad notable. En Cremona, el dirigente popular Miglioli era conocido como el "bolchevique blanco», y no era el único. La estrategia "paternalista" basada por un lado en el control de las categorías intermedias, y por otro en la mediación gubernamental, fue definitivamente derrotada.

Por último, en el Mezzogiorno se produjo un gran movimiento de ocupación de tierras, en buena medida espontáneo y conectado con las antiguas reivindicaciones sobre las tierras comunales, pero a menudo capitaneado por organizadores católicos, combatientes y también socialistas. En el plano político estos movimientos fueron en parte absorbidos por el dúctil mecanismo caciquil, que consiguió incluso expresar nuevos intereses colectivos, de lo que fueron buena muestra las cooperativas campesinas para el cultivo del latifundio siciliano, que a menudo se convirtieron en una nueva fuente de poder para los mafiosos. A pesar de todo, la ocupación de tierras contribuyó notablemente a aumentar los temores de la clase propietaria y el sentimiento de inseguridad general.

El Valle del Po fue, sin embargo, el lugar donde se desarrolló la decisiva reacción fascista. El liderazgo de los terratenientes cayó en manos de hombres como Carrara, típicos burgueses emprendedores en vez de antiguos propietarios nobles. Su consigna de la "colaboración de clases» expresaba algo muy distinto a lo que cabía pensar. Indicaba la creación de organizaciones subordinadas de trabajadores "colaboracionistas" y el rechazo al reconocimiento de las ligas. Era una política que sólo podía llevarse a cabo con la violencia, y fue aquí donde la ayuda del fascismo se convirtió en indispensable. También es cierto que el fascismo y los terratenientes jugaron hábilmente con las aspiraciones de los campesinos a poseer propiedades individuales, mientras que los socialistas permanecieron fieles al programa de colectivización. La primera uruptura» se cumplió con estos métodos en Ferrara, en Mantua, en Bolonia. Una vez que había sido demostrada la eficacia del "modelo", podía aplicarse también en circustancias distintas. En Toscana y en Umbría fueron en gran medida los miembros de la vieja clase propietaria los que capitanearon la reacción, y no una nueva clase. Y la reacción fascista fue incluso más violenta y brutal porque no hizo concesiones, sino que se centrć sencillamente en el restablecimiento de las antiguas relaciones de sumisión. De todos modos la derrota total de las ligas se realizó con la complicidad ramificada, local, sin bien se realizaba bajo los ojos benévolos de la clase política liberal y del gobierno, en realidad minaba las bases de su poder. 
Esta consideración me lleva a un último tema importante, al que me referiré brevemente: el papel de la violencia política. La aceptación del uso de la violencia privada en la política representó la ruptura decisiva con el funcionamiento normal del estado moderno. Además, en el caso del fascismo, la violencia privada sirvió de principal instrumento aglutinador.

La guerra sin duda hizo aumentar la violencia y cambió su carácter. Se dio un aumento generalizado de la violencia en 1919, que no puede atribuirse al fascismo, pero que coincide a grandes rasgos con la desmovilización del ejército. También las antiguas luchas caciquiles y mafiosas se hicieron más feroces. Las expectativas habian aumentado mientras que los recursos habían disminuido, y esto creó conflictos tanto en el plano social como individual. Este clima de desorden y de violencia creó un clima psicológico favorable al fascismo, que utilizaba la violencia sin ningún tipo de prejuicio, pero a la vez prometía el restablecimiento del orden. Sin embargo no se debe confundir en absoluto esta violencia difusa con el nuevo tipo de violencia planificada, estratégica, de tipo paramilitar, introducida por el fascismo, que constituyó una gran innovación para la que el estado liberal no estaba ni siquiera técnicamente preparado.

Ante esta violencia se produjo la "retirada del estado", dejándose así un amplio terreno a los escuadrones fascistas. La ambigüedad de la dirección política favoreció la colusión y la falta de acción. Si bien Giolitti daba instrucciones a los prefectos para reprimir la violencia, a la vez eliminaba su credibilidad aliándose con el movimiento fascista en los «bloques nacionales" en las elecciones de 1921. Se aprecia claramente en la política giolittiana, tras las desilusiones sufridas por la falta de colaboración socialista, el proyecto de reducir el peso de los partidos de masas, socialistas y populares. Pero no se podía utilizar a los fascistas, como en otros tiempos se hacía con los llamados mazzieri del sur, con fines electorales sin más. Ni se podía cooptarlos o colaborar con ellos de forma estable en el seno del estado liberal. Hubo algunos intentos en este sentído, animados por el propio Mussolini, y por una parte del movimiento fascista, sobre todo urbano, pero fracasaron ante la intransigencia y la nueva estrategia paramilitar y sindical del fascismo agrario. Por tanto, si se concede más peso a la crisis agraria que a la industrial como factor de desintegración del estado liberal, no es sólo una cuestión que se deba al nacimiento del fascismo, sino también a las diversas formas y corrientes del movimiento. Es decir, el fascismo agrario, sabía que su dominio era irreconciliable con el estado liberal, mientras que el fascismo de las clases medias tenía unos objetivos más limitados.

La última "ocasión perdida" del estado liberal fue la del Pacto de $\mathrm{Pa}$ cificación de 1921 entre fascistas y socialistas. A pesar de la gran división 
interna del movimiento fascista, —en la que Mussolini se alineó en contra de los fascistas agrarios y extremistas-, el gobierno no logró intervenir decisivamente en la situación. Entre 1921 y 1922 se asistió a una verdadera desintegración del estado. En este sentido, únicamente, el fascismo actuó como una fuerza "revolucionaria", si bien era una revolución de tipo nuevo, desde la derecha. Resulta evidente que el fascismo consiguió substituir al régimen liberal no sólo con la violencia y con la desintegración del estado, sino que también atrajo y englobó en su sistema a gran parte de la base social del propio liberalismo, y estrechó una serie de alianzas con las elites principales.

Aquellos industriales y aquellos terratenientes que formalmente conservaron su fidelidad tradicional a los viejos jefes parlamentarios, en su mayoría lo hicieron sólo porque éstos no rompieron con el fascismo. El dirigente conservador Salandra descubrió demasiado tarde esta amarga verdad al producirse la crisis Matteotti. La Iglesia sacrificó al Partido Popular por las ventajas de una relación nueva y directa con el estado. Las clientelas meridionales pasaron al vencedor, $y$ al final tuvieron que aceptar una nueva relación con un estado y un partido mucho más centralizado, que en cierto modo anticipaba las formas más modernas del caciquismo partidista de la posguerra. En todas las organizaciones la jerarquía substituyó a la democracia como principio fundamental. De esta forma el fascismo consiguió tener bajo su control a toda la sociedad italiana sin crear una organización plenamente totalitaria.

Una última observación, brevísima, sobre un tema que merecería una atención mucho más amplia. Me parece que hubo dos grandes «ocasiones perdidas» en la posguerra que están interrelacionadas. Una es la existencia de un partido católico de tipo democrático y no autoritario. La segunda, en el plano social, es que se habia producido un gran traspaso de propiedad a los campesinos, incluso sin la reforma agraria general que había sido prometida durante la guerra. De 1911 a 1929 los cultivadores directos pasaron de un 18 por cien a un 30 por cien de la población agrícola. Alrededor de 2.500.000 hectáreas pasaron a manos de 500.000 nuevos propietarios. Podría haber sido la base de una nueva "democracia rural", y en las zonas católicas esta posibilidad se había realizado a un nivel local. Pero en su conjunto cuando los métodos tradicionales de control dejaron de funcionar, no hubo ninguna fuerza política capaz de superar la crisis y sentar las bases de una democracia efectiva. 